
DOI: http://dx.doi.org/10.4314/njbas.v24i1.7

\title{
Preparation of High Grade Silica from Rice Husk for Zeolite Synthesis
}

\author{
*1S. Yunusa, 1A.S. Ahmed, 1S.G. Bawa, 2J.F. lyun and ${ }^{3}$ M. Dauda \\ 1 Department of Chemical Engineering, Ahmadu Bello University, Zaria, 810261, Nigeria \\ 2Department of Chemistry, Ahmadu Bello University, Zaria, 810261, Nigeria \\ 3Department of Mechanical Engineering, Ahmadu Bello University, Zaria, 810261, Nigeria \\ [Corresponding author: slmnyunus@gmail.com: E : +2348038951472]
}

\begin{abstract}
Silica powder with approximately $96 \%$ purity was extracted from rice husk $(\mathrm{RH})$ and used as a silica source for the synthesis of zeolite $Y$ by hydrothermal process. The effect of synthesis parameters such as $\mathrm{pH}$, temperature of burning the rice husk, acid leaching prior to formation of rice husk ash (RHA) on the properties of final product were studied. The acid-leached rice husk calcined at $650{ }^{\circ} \mathrm{C}$ for $6 \mathrm{~h}$ produced rough powder of rice husk silica, light brown in colour. The silica purity of the rice husk ash (RHA) calcined at 400,450 and $500^{\circ} \mathrm{C}$ were $95.6 \mathrm{wt} \%, 96.1 \mathrm{wt} \%$ and $95.89 \mathrm{wt} \%$ respectively. The X-Ray Diffraction (XRD) pattern of the silica obtained show that the silica was amorphous with traces of crystalline phase. The amorphous nature of the RHA and the relatively high purity of silica content in it make it a suitable source of silica for zeolite synthesis.

Keywords: Silica; RHA; Zeolite; Synthesis; Hydrothermal; Temperature
\end{abstract}

\section{INTRODUCTION}

Rice Husk $(\mathrm{RH})$ is a solid waste product from rice milling industries (Kordatos et al., 2008). Rice Husk Ash (RHA) derived from burning $\mathrm{RH}$ is one of the most silica rich raw materials containing about $90-98 \%$ silica after complete combustion, highly porous and lightweight, with a very high external surface area. Its absorbent and insulating properties are useful to many research studies (Mittal, 1997; Kordatos et al., 2008). About 20\% of the rice husk ash residues left after the combustion cause environmental problems due to the pollution of both water and air (Kordatos et al., 2008, Rahman et al., 2009). Although, hosts of synthetic silica are produced commercially, the ones produced from plant origins such as rice husks have been noted to have some significant advantages over those from mineral and synthetic origins. In particular, the processing steps are relatively simple and require no elaborate infrastructure or consumption of costly reagents as in the case of the synthetic processes. In addition the silica powder produced from plant sources contains a narrow range of metal oxide impurities (Edson et al., 2006) which makes them exceptionally desirable in applications where high purity silica at modest cost is a necessary prerequisite. Rice husk is largely composed of silica with small amounts of inorganic compounds. In practice, the type of ash from rice husk varies considerably according to the burning technique. Previous research had shown that pure silica can be obtained from rice husk by acid leaching procedure and calcination at $600{ }^{\circ} \mathrm{C}$ under atmospheric pressure. This process is considered expensive, due to the energy consumption (Edson et al., 2006). Hydrochloric acid is most often used for acid leaching (Rahman et al., 2009, Johan et al., 2011). The extraction of silica from rice husk by acid treatment provides more than $95 \%$ by weight of amorphous silica (Suyanta and Kuncaka et al., 2011).

Silica $\left(\mathrm{SiO}_{2}\right)$ is one of the valuable inorganic multipurpose chemical compounds. It can exist in gel, crystalline and amorphous forms. Amorphous silica is a naturally occurring or synthetically produced oxide of silicon characterized by the absence of a pronounced crystalline structure and whose X-ray diffraction patterns have no sharp peaks (Larbi, 2010). This type of silica may be anhydrous or have a significant water of hydration in its structure. In general, rice husk ash (RHA) might well be considered slightly impure silica. The content of silica and all impurities in RHA varies, depending on the variety, climate and geographic location (Larbi, 2010). Amorphous silica is well known and commonly used as a silica source in the synthesis of micro-porous materials such as zeolites, silica gel etc (Adam et al., 2006). However, to obtain pure amorphous silica is energy intensive as it requires high furnace temperature (Mittal et al., 1997). Previous research work (Rahman et al., 2009) had shown that pure silica can be obtained from $\mathrm{RH}$ by an acid leaching procedure and pyrolysis in an oxygen atmosphere at $500^{\circ} \mathrm{C}$ for $5 \mathrm{hrs}$. This paper is aimed at preparation of high grade amorphous silica in an oxygen environment at lower temperature. 


\section{EXPERIMENTAL \\ Purification Treatment of Rice Husk (RH) Leaching of $\mathrm{RH}$}

Rice husk was sieved to eliminate clay particle. This was washed with distilled water and dried in an oven at $100^{\circ} \mathrm{C}$ for $24 \mathrm{hrs}$. Acid leaching of the rice husk was carried out to remove soluble elemental impurities such as iron, magnesium, calcium etc. Leaching was carried out at $10 \mathrm{wt} \%$ solids in $10 \mathrm{wt} \% \mathrm{HCl}$. The $\mathrm{HCl}$ solution was prepared from a standard $\mathrm{HCl}$ stock of mean concentration of $37 \mathrm{wt} \%$ and density of $1.19 \mathrm{~g} / \mathrm{ml}$. The dried $\mathrm{RH}$ was soaked in the prepared solution of $10 \mathrm{wt} \%$ $\mathrm{HCl}$ for $24 \mathrm{hrs}$. The treated rice husk was washed again thoroughly with distilled water until $\mathrm{pH}$ became 7 and then dried at $100{ }^{\circ} \mathrm{C}$ for $24 \mathrm{hrs}$.

\section{Pyrolysis of RH}

The dried $\mathrm{RH}$ was pyrolyzed in an oxygen atmosphere at $500^{\circ} \mathrm{C}, 450^{\circ} \mathrm{C}$ and $400^{\circ} \mathrm{C}$ respectively for 6 hours. The RHA obtained was characterized using Empyreal PANalytic Diffractometer, using $\mathrm{Cu} \mathrm{Ka}$ radiation and Munipal 4 Energy Dispersed- X ray fluorescence (EDXRF) machine for mineralogy and chemical compositions respectively.

\section{Zeolite Synthesis}

The three major Steps involves in synthesis of zeolite $Y$ are Seeding gel, Feedstock gel and over all gel.

\section{Preparation Seed Gel}

About $1.7 \mathrm{~g}$ sodium hydroxide pellets were dissolved in $7.5 \mathrm{ml}$ deionized water and stirred until clear and homogenous solution appeared. $2 \mathrm{ml}$ of the aqueous $\mathrm{NaOH}$ were added to $0.75 \mathrm{~g}$ sodium aluminate and stirred with heating until a homogenous mixture was formed. $1.5 \mathrm{~g}$ silica source (RHA, cab-0-sil and sodium metasilicate) were added separately to $5.5 \mathrm{ml}$ sodium hydroxide aqueous and stirred while heating on the magnetic stirrer until homogenously mixed (Rahman et al., 2009). The two solutions were then mixed simultaneously in a $150 \mathrm{ml}$ propylene bottle and stirred with heating for 30 minutes. The gel formed was then age for $24 \mathrm{hrs}$.

\section{Preparation of Feedstock Gel}

About $7.8 \mathrm{~g} \mathrm{NaOH}$ pellets were dissolved in $142 \mathrm{ml}$ distilled water and stirred until a clear solution formed. $42.5 \mathrm{ml}$ of $\mathrm{NaOH}$ solution were added to $13.7711 \mathrm{~g}$ sodium aluminate and stirred with heating gently on the hot plate until clear solution appeared then $28.1463 \mathrm{~g}$ silica source (RHA, cab-o-sil and sodium metasilicate) were added to $100 \mathrm{ml}$ of $\mathrm{NaOH}$ solution in a polypropylene bottle. The mixture was then stirred and heated on the hot water bath. The aluminate and silicate solutions formed were then mixed together in a polypropylene bottle and stirred for $2 \mathrm{hrs}$.

\section{Preparation of Overall Gel}

The seed gel and feed stock gel were then mixed. The seed gel was added slowly into the feed stock gel and the mixture was continuously stirred with magnetic stirrer for $2 \mathrm{hrs}$ at room temperature. The mixture was then transferred into $150 \mathrm{ml}$ propylene bottle and was aged for $24 \mathrm{hrs}$ at room temperature. After ageing, the mixture was inserted into oven at $100^{\circ} \mathrm{C}$ for $22 \mathrm{hrs}$. The propylene bottle was removed after $22 \mathrm{hrs}$ in the oven and the cap was quickly opened and left to cool to room temperature. After cooling the mixture was, filtered and washed with hot de-ionized water, then dried overnight in the oven at $100^{\circ} \mathrm{C}$

\section{RESULTS AND DISCUSSION XRD Results}

Figures 1 (a-c) present the XRD patterns of the resulting RHA obtained at calcination temperatures of 400,450 and $500^{\circ} \mathrm{C}$ respectively. From the XRD patterns the broad peaks at $2 \theta$ angle range of $18-30^{\circ}$ and low intensity counts confirmed the RHA to be largely amorphous silica, which is suitable for zeolite synthesis than the crystalline phase because amorphous silica is very soluble in alkaline medium. However, a sharp peak appears at $2 \theta$ value of about $26^{\circ}$ which indicates the presence of quartz, a crystalline phase. The presence of quartz might have resulted from the fine particles of it that could not be trapped during the sieving of the rice husk at the treatment stage. The RHA obtained at $4000^{\circ} \mathrm{C}$ and $450^{\circ} \mathrm{C}$ are more amorphous as shown in Figures $1(a)$ and (b) respectively, than the sample obtained at $500^{\circ} \mathrm{C}$ presented in Figure1 (c). This observation agrees with literature, that at higher temperatures, an orderly arrangement of the silica molecules occurs which makes it crystalline.

\section{X-Ray Fluorescence (XRF) Analysis}

A chemical composition of RHA was determined using XRF technique as shown in Table 1. The chemical compositions of RHA sample in oxides form with silica content of $95.6 \mathrm{wt} \%, 96.1 \mathrm{wt} \%$ and $95.89 \mathrm{wt} \%$ at calcination temperatures of $400^{\circ} \mathrm{C}, 450^{\circ} \mathrm{C}$ and $500^{\circ} \mathrm{C}$ respectively. Furthermore, it was observed that the silica obtained at calcination temperatures of $400^{\circ} \mathrm{C}$ and 
$450^{\circ} \mathrm{C}$ is alumina free. The silica obtained at calcination temperature of $400^{\circ} \mathrm{C}$ when used as silica source for the synthesis of zeolite $Y$ (Figure 2 (a)) matched well when compared to the XRD pattern of standard zeolite Y (Figure 2(b)).
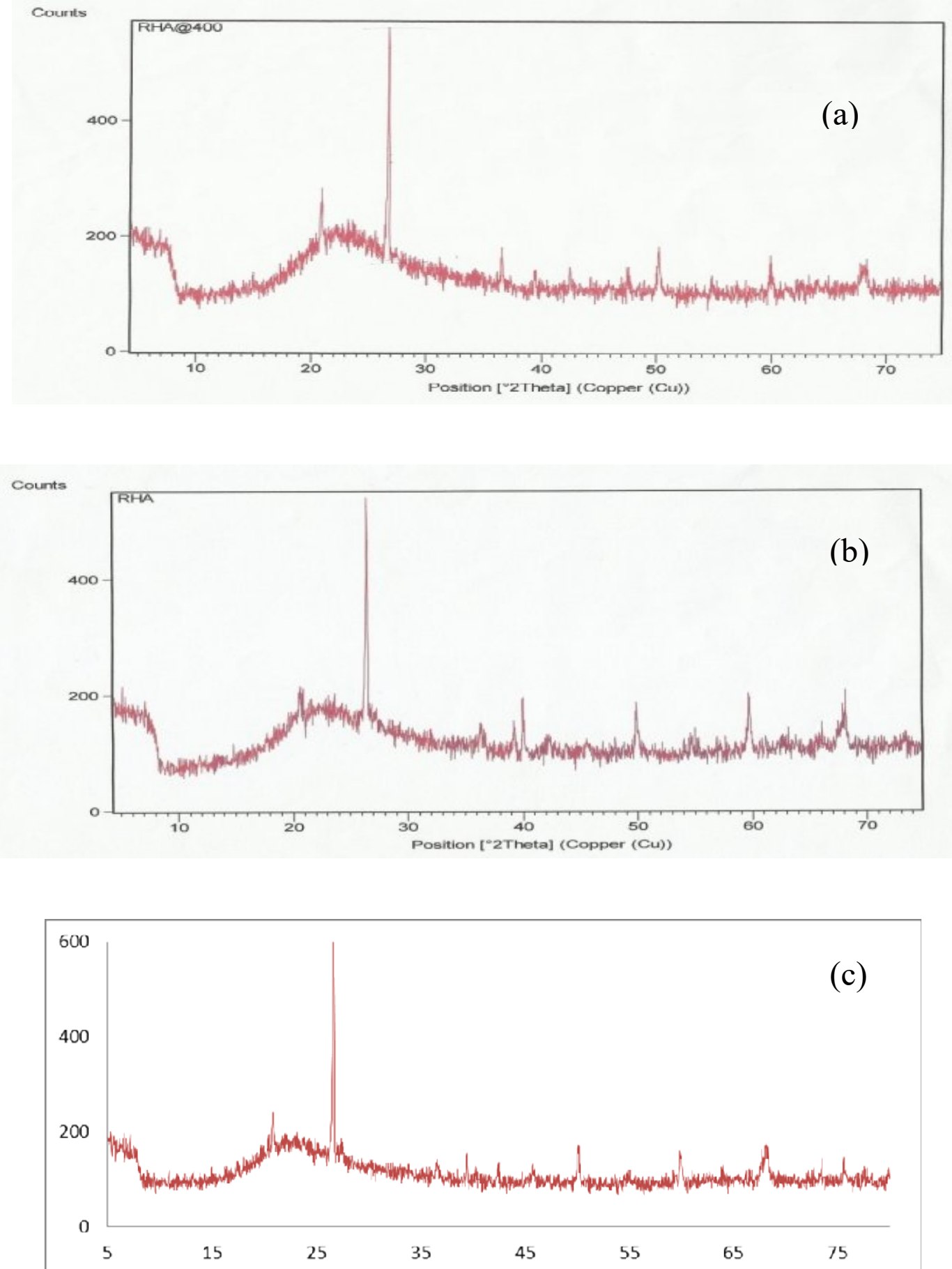

Figure 1: Rice Husk Ash produced at different temperatures (a) $400^{\circ} \mathrm{C}$, (b) $450^{\circ} \mathrm{C}$ and (c) $500^{\circ} \mathrm{C}$ 

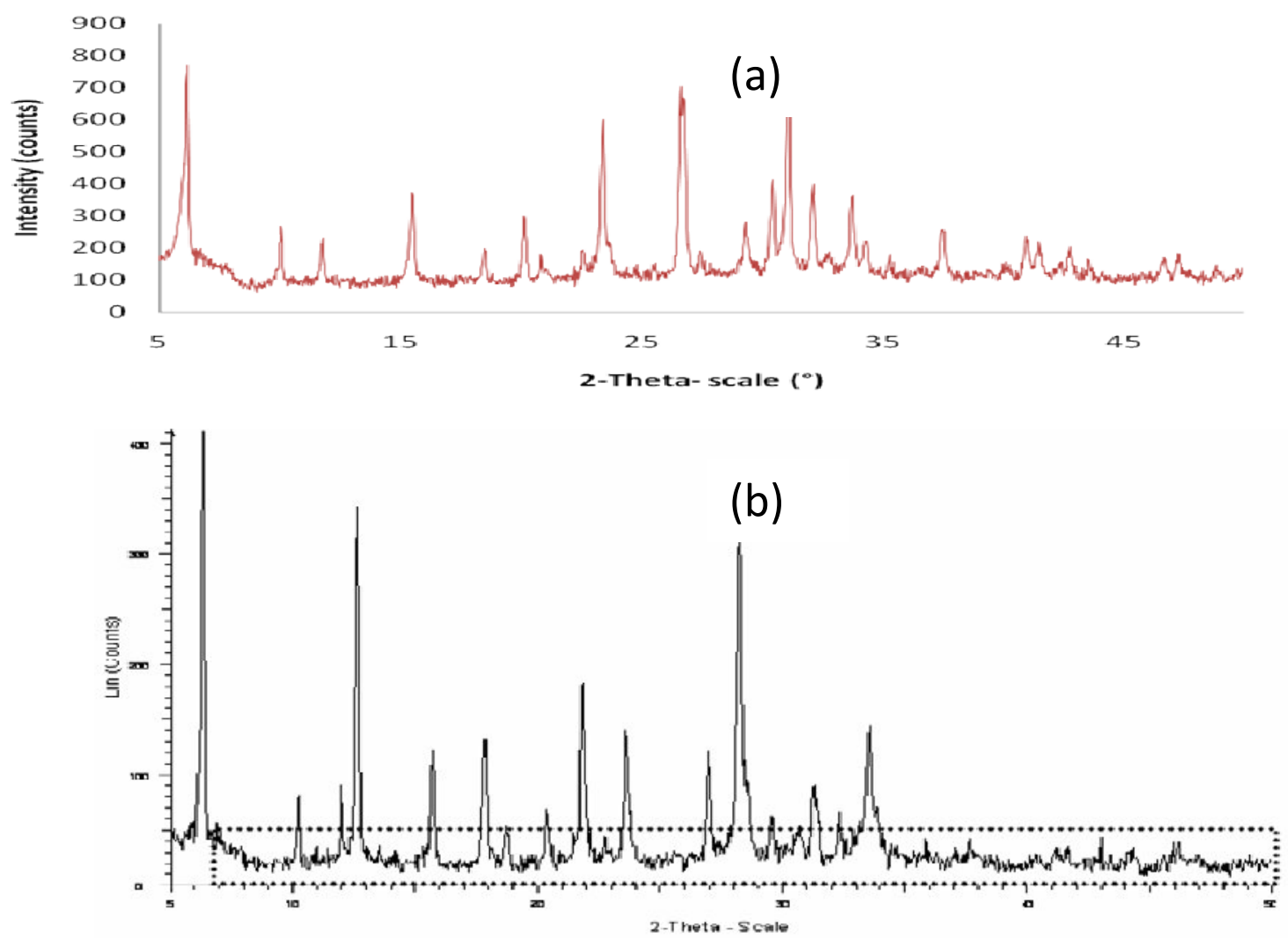

Figure 2: XRD pattern of (a) RHA based Zeolite $Y$ and (b) standard Zeolite $Y$

Table 1: Chemical composition of Rice Husk Ash

\begin{tabular}{ccccccccc}
\hline & \multicolumn{7}{c}{ Oxides (\%) } \\
\cline { 2 - 8 } Temperature & $\mathrm{SiO}_{2}$ & $\mathrm{Al}_{2} \mathrm{O}_{3}$ & $\mathrm{CaO}$ & $\mathrm{K}_{2} \mathrm{O}$ & $\mathrm{Na}_{2} \mathrm{O}$ & $\mathrm{LO}$ & Other component & Total \\
\hline $400^{\circ} \mathrm{C}$ & 95.6 & nd & 0.59 & 0.65 & 0.04 & nd & 2.36 & 99.24 \\
$450^{\circ} \mathrm{C}$ & 96.1 & nd & 0.41 & 0.57 & 0.31 & 0.98 & 2.54 & 99.93 \\
$500^{\circ} \mathrm{C}$ & 95.89 & 0.91 & 0.39 & 0.27 & 0.11 & 0.99 & 2.41 & 99.98 \\
\hline
\end{tabular}

$\mathrm{nd}=$ Not detected

\section{CONCLUSION}

It may be concluded from the investigations carried out that a simple and low energy method has been developed to produce highly amorphous silica of $96.1 \mathrm{wt} \%$ purity from rice husk pyrolysed in an oxygen atmosphere at $450^{\circ} \mathrm{C}$. The silica obtained could be suitable for chemical synthesis such as preparation of zeolite. The zeolite $Y$ prepared from RHA compares favorably with standard zeolite $Y$.

\section{ACKNOWLEDGMENT}

The authors gratefully acknowledge the Petroleum Technology Development Fund (PTDF), Abuja-Nigeria, for supporting this research work.

\section{REFERENCES}

Adam, F., Balakrishnan, S. and Wong, P. (2006). Rice Husk Ash Silica as a Support Material for Ruthenium based Heterogenous Catalyst. Journal of Physical Science, 17(2): 1-13.

Edson, L.F., Ederson, G.L., Hadlich de, O. and Sérgio, L.J. (2006). Conversion of rice hull ash into soluble sodium silicate. Materials Research, 9(3): 335-338

Jezreel J., Saceda F. and Leon R. (2011). Properties of Silica from Rice Husk and Rice Husk and their Utilization for Zeolite Y Synthesis. Quim Nova, 34(8): 1394-1397.

Khemthong, P., Prayoonpokarach, S and Wittayakun, J. (2007). Synthesis and Characterization of Zeolite 
$\mathrm{NaY}$ from Rice Husk Silica. Korean Journal of Chemical Engineering, 25(4): 861-864.

Kordatos K., Gavela S., Ntziouni A., Pistiola K.N., Kyritsi A. and Kasselouri- Rigopoulou V. (2008). Synthesis of highly siliceous ZSM-5 zeolite using silica from rice husk ash. Microporous and Mesoporous Materials, 115(1\&2): 189-196.

Larbi, K.K. (2010). Synthesis of High Purity Silicon from Rice Husks; Master of Applied Science, Department of Materials Science and Engineering, University of Toronto. https://tspace.library.utoronto.ca/bitstream/1807/2 4595/1/Larbi_Kingsley_K_MASc_thesis.pdf.

Mittal, D. (1997). Silica from ash a valuable product from waste material. Resonance, 2(7): 64-66.
Johan, E., Ogami, E., K, Abidin Z., Matsue N. and Henmi T. (2011). Synthesis of Zeolite MFI from Rice Husk Ash and its Ability for VOCs Adsorption.http://www.ibrarian.net/navon/page.jsp ?paperid=18285525.

Rahman M. M., Hasnida N. and Wan Nik W.B. (2009) Preparation of Zeolite Y Using Local Raw Material Rice Husk as a Silica Source, Journal of Scientific Research, 1(2): 285-291.

Suyanta, S. and Kuncaka, A. (2011). Utilization of Rice Husk as Raw Material in Synthesis of Mesoporous Silicates MCM-41 Indonesian Journal of Chemistry, 11(3): $279-284$. 